\title{
A novel and simple method for generation of human dendritic cells from unfractionated peripheral blood mononuclear cells within 2 days: its application for induction of HIV-1-reactive $\mathrm{CD}^{+}{ }^{+} \mathrm{T}$ cells in the hu-PBL SCID mice
}

\author{
Akira Kodama ${ }^{1}$, Reiko Tanaka ${ }^{1}$, Mineki Saito ${ }^{2}$, Aftab A. Ansari ${ }^{3}$ and Yuetsu Tanaka ${ }^{1 *}$ \\ ' Department of Immunology, Graduate School of Medicine, University of the Ryukyus, Okinawa, Japan \\ 2 Department of Microbiology, Kawasaki Medical School, Kurashiki, Japan \\ ${ }^{3}$ Department of Pathology, Emory University School of Medicine, Atlanta, GA, USA
}

\section{Edited by:}

Akio Adachi, The University of

Tokushima Graduate School, Japan

\section{Reviewed by:}

Bernard A. P. Lafont, National Institute of Allergy and Infectious Diseases, National Institutes of Health, USA Yasuko Tsunetsugu Yokota, National Institute of Infectious Diseases, Japan

\section{*Correspondence:}

Yuetsu Tanaka, Department of Immunology, Graduate School of Medicine, University of the Ryukyus, 207 Uehara, Okinawa 903-0215, Japan

e-mail: yuetsu@s4.dion.ne.jp
Because dendritic cells (DCs) play a critical role in the regulation of adaptive immune responses, they have been ideal candidates for cell-based immunotherapy of cancers and infections in humans. Generally, monocyte-derived DCs (MDDCs) were generated from purified monocytes by multiple steps of time-consuming physical manipulations for an extended period cultivation. In this study, we developed a novel, simple and rapid method for the generation of type-1 helper T cell (Th1)-stimulating human DCs directly from bulk peripheral blood mononuclear cells (PBMCs). PBMCs were cultivated in the presence of $20 \mathrm{ng} / \mathrm{ml}$ of granulocyte-macrophage colony-stimulating factor, $20 \mathrm{ng} / \mathrm{ml}$ of interleukin-4 (IL-4) and $1,000 \mathrm{U} / \mathrm{ml}$ of interferon- $\beta$ for $24 \mathrm{~h}$ followed by $24 \mathrm{~h}$ maturation with a cytokine cocktail containing $10 \mathrm{ng} / \mathrm{ml}$ of tumor necrosis factor- $\alpha$ (TNF- $\alpha$ ), $10 \mathrm{ng} / \mathrm{ml}$ of IL-1 $\beta$ and $1 \mu \mathrm{g} / \mathrm{ml}$ of prostaglandin E2. The phenotype and biological activity of these new DCs for induction of allogeneic T cell proliferation and cytokine production were comparable to those of the MDDCs. Importantly, these new DCs pulsed with inactivated HIV-1 could generated HIV-1reactive $\mathrm{CD}^{+}{ }^{+} \mathrm{T}$ cell responses in humanized mice reconstituted with autologous PBMCs from HIV-1-negative donors. This simple and quick method for generation of functional DCs will be useful for future studies on DC-mediated immunotherapies.

Keywords: dendritic cell, short-term culture, Th1-inducing DCs, anti-HIV-1T cell response, hu-PBL-SCID

\section{INTRODUCTION}

Dendritic cells (DCs) are professional antigen-presenting cells (APCs) which play a critical role in the regulation of the adaptive immune response through activation and polarization of naive $\mathrm{T}$ cells (Banchereau et al., 2000). Since small numbers of activated DCs are highly efficient in generating immune responses against infections and cancers (Moll and Berberich, 2001; Steinman and Banchereau, 2007), the DC therapy represents a new and promising immunotherapeutic approach for treatment of advanced cancers as well as for prevention of infectious diseases. Indeed, the current clinical trials with ex vivo-generated DCs (socalled DC vaccine) will yield precious information regarding their potentials as vectors for immunotherapy (Gilboa, 2007; Connolly et al., 2008; Ezzelarab and Thomson, 2011). However, the general protocols to generate DCs are complicated and time consuming. Moreover, since different ex vivo DC generation methods affect the DC phenotype and function (Kalantari et al., 2011), it is critical to choose appropriate method for generating functional DCs. In general, the DC precursor monocytes are purified from PBMCs by adherence (Jonuleit et al., 2001), elutriation (Berger et al., 2005) or positive or negative selection using immunomagnetic beads (Babatz et al., 2003). These enriched monocytes are then induced to differentiate into DCs by 5 days-in vitro cultivation in medium supplemented with granulocyte macrophage colony-stimulating factor (GM-CSF) and interleukin (IL)-4 followed by a 2-daysmaturation procedure (Sallusto and Lanzavecchia, 1994; Gilboa, 2007; Dauer et al., 2008). However, a lines of evidence are increasing that mature monocyte-derived DCs can be generated even after short-term cell culture for 2-3 days (Dauer et al., 2003a,b; Jarnjak-Jankovic et al., 2007; Zhang et al., 2008; Tawab et al., 2009).

In this study, in an attempt to simplify the methods currently being used for optimal DC generation and to develop a standardized method of preparing effective myeloid DC vaccine for immunotherapies, we explored the efficacy of using unfractionated PBMCs as a source of DC precursors and short-term in vitro cell culture just for 2 days.

\section{MATERIALS AND METHODS REAGENTS}

The media used were RPMI 1640 medium (Sigma, St. Louis, MO, USA) supplemented with $10 \%$ fetal calf serum (FCS; Sigma, St. Louis, MO, USA), $100 \mathrm{U}$ of penicillin per $\mathrm{ml}$, and $100 \mu \mathrm{g}$ of streptomycin per ml (hereafter called RPMI medium) and Iscove's modified Dulbecco's medium (Lifetechnologies, Grand Island, 
NY, USA) supplemented with 10\% FCS with the same antibiotics (hereafter called Iscove's medium). Aldrithiol-2 (AT-2) and low-endotoxin bovine serum albumin (BSA) was purchased from Sigma (St. Louis, MO, USA). The recombinant human cytokines used included IL-4, GM-CSF, TNF- $\alpha$ and IL-1 $\beta$ (PeproTech, London, UK). Enzyme-linked immunosorbent assay (ELISA) kits for the quantitation of human IFN- $\gamma$, human IL-4, human IL-10 and human IL-12 (detecting IL-12 p75 heterodimer) were purchased from Biolegend. The human monocyte negative isolation kits and the human $\mathrm{T}$ cell isolation kits were purchased from Invitrogen (Carlsbad, CA, USA). The human naive $\mathrm{CD} 4^{+} \mathrm{T}$ cell isolation kit was purchased from Miltenyi Biotec (Gladbach, Germany). The Vybrant CFDA SE Cell Tracer Kit was purchased from Invitrogen.

\section{GENERATION OF DCs}

Human PBMCs were isolated from heparinized peripheral blood obtained from normal healthy adult volunteer donors by standard density gradient centrifugation. Cells at the interface were collected and washed three times in cold phosphate-buffered saline (PBS) containing $0.1 \%$ low-endotoxin BSA and $2 \mathrm{mM} \mathrm{Na}_{2}$ EDTA. For select experiments, monocytes were purified from PBMCs using the $\mathrm{CD}_{14}{ }^{+}$monocyte negative isolation kit (Invitrogen, Carlsbad, CA, USA). An aliquot of cells from each monocyte preparation was examined by flow cytometry and found to contain $>90 \% \mathrm{CD} 14^{+}$cells. To obtain immature MDDCs (iMDDCs), PBMCs $\left(2.5 \times 10^{6}\right.$ cells $\left./ \mathrm{ml}\right)$ or the purified monocytes $\left(5 \times 10^{5}\right.$ cells $/ \mathrm{ml}$ ) were cultured in RPMI medium containing $20 \mathrm{ng} / \mathrm{ml}$ of human GM-CSF and $20 \mathrm{ng} / \mathrm{ml}$ of human IL- 4 at $37^{\circ} \mathrm{C}$ in 24 -well plates in a $5 \% \mathrm{CO}_{2}$ humidified incubator for 5 days. In other experiments, iDCs were generated from either purified monocytes or whole PBMCs by cultivation in RPMI medium containing GMCSF (20 ng/ml), IL-4 (20 ng/ml) and IFN- $\beta$ ( $1,000 \mathrm{U} / \mathrm{ml})$ for 1 day. These iDCs were matured by incubation in the presence of either $10 \mathrm{ng} / \mathrm{ml}$ of LPS (Sigma) or a cocktail containing $10 \mathrm{ng} / \mathrm{ml}$ of TNF$\alpha, 10 \mathrm{ng} / \mathrm{ml}$ of IL- $1 \beta$ and $1 \mu \mathrm{g} / \mathrm{ml}$ of prostaglandin E2 (PGE2; TIP cocktail) for 1-2 days.

\section{FLOW CYTOMETRY}

Aliquots of the cells to be analyzed were incubated in PBS containing $0.1 \%$ BSA and $0.1 \%$ sodium azide (FACS buffer) supplemented with $2 \mathrm{mg} / \mathrm{ml}$ normal human IgG on ice for $15 \mathrm{~min}$ to block Fc receptors. The cell suspension was then incubated with a predetermined optimal concentration of the appropriate fluorescent dye-labeled mAbs against human cell surface markers on ice for $30 \mathrm{~min}$. The fluorescent dye-labeled monoclonal antibodies (mAbs) against human cell surface molecules used included anti-CD3, anti-CD4, anti-CD8, anti-CD14, CD20, anti-CD80, anti-HLA-DR, and isotype-matched control mAbs (Beckman Coulter, Fullerton, CA, USA), and anti-CD11c, anti-CD86, and anti-CD83 (BioLegend, San Diego, CA, USA). After washing with FACS buffer, cells were fixed in 1\% paraformaldehyde (PFA) containing FACS buffer. The cells were then analyzed on FACS-Calibur flow cytometer with CellQuest software (BD Pharmingen, San Diego, CA, USA). Isotype-matched mAbs were utilized as controls to stain an aliquot of the cells to be analyzed for purposes of establishing gates and for determination of the frequency of positively stained cells.

\section{HIV-1 PREPARATION AND INACTIVATION}

HIV-1 $1_{\text {IIIB }}$ (virus that only use CXCR4 as chemokine co-receptor, termed X4) was harvested from Molt-4/IIIB cell cultures. Batches of each HIV-1 preparation were inactivated with Aldrithiol-2 (AT2; Sigma) as described previously (Yoshida et al., 2003). AT-2 was removed by three successive ultrafiltration in PBS using $100-\mathrm{kDa}$ cut-off centrifugal filtration devices (Centriprep 100; Amicon, Beverly, MA, USA). Then AT-2-inactivated HIV-1 (iHIV) was purified by pelleting down the virus at $20,000 \times g$ for $2 \mathrm{~h}$ three times in $0.1 \%$ BSA-PBS. The virus pellet was resuspended in $0.1 \%$ BSA-PBS, aliquoted, and stored at $-80^{\circ} \mathrm{C}$ until use. The concentration of HIV-1 was estimated by measuring levels of HIV-1 p24 antigen with our in-house p24 ELISA kit (Tanaka et al., 2010). As previously described (Yoshida et al., 2003), activated human PBMCs incubated with an aliquot of $1 \mu \mathrm{g} / \mathrm{ml}$ of the AT-2-treated HIV-1 preparation failed to demonstrate the presence of any detectable infectious virions (data not shown).

\section{STIMULATION OF T CELLS}

Enriched populations of naive $\mathrm{CD}^{+} \mathrm{T}$ cells and bulk $\mathrm{T}$ cells with $>90 \%$ purity were isolated from normal human PBMCs by using appropriate negative cell isolation kits. These $\mathrm{T}$ cells $\left(4 \times 10^{4}\right.$ cells/well) were first labeled with carboxy-fluorescein diacetate succinimidyl ester (CFSE) according to the manufacturer's instructions (Invitrogen, Carlsbad, CA, USA), then co-cultured with allogeneic DCs at a T cells: DCs ratio of 50:1 in $100 \mu \mathrm{l}$ of RPMI medium supplemented with $20 \mathrm{U} / \mathrm{ml}$ human IL-2 in 96-well, U-bottomed plates. Cell proliferation and cytokine production were determined on day 4 .

\section{hu-PBL-SCID MICE}

The BALB/c-rag2 $2^{-/} \gamma \mathrm{c}^{-/-}$mice lacking T cells, B cells and natural killer (NK) cells (Rag2-/- mice; Traggiai et al., 2004) were used in this study. The mice were kept in the specific-pathogen-free and P3 animal facilities of the Laboratory Animal Center, University of the Ryukyus. The protocols for the care and use of mice engrafted with human PBMCs and autologous DCs sensitized with inactivated HIV-1 or ovalbumin (OVA) were approved by the committee on animal research of the University of the Ryukyus prior to initiation of the study. Matured DCs $\left(5 \times 10^{5}\right.$ cells $)$ pulsed with either AT-2-inactivated HIV-1 (40 ng of p24) or $100 \mu \mathrm{g}$ of OVA in $100 \mu \mathrm{l}$ of RPMI medium for $2 \mathrm{~h}$ at $37^{\circ} \mathrm{C}$ were mixed with autologous fresh PBMCs $\left(3 \times 10^{6}\right.$ cells $)$ in a final volume of $100 \mu \mathrm{l}$ in serum-free RPMI medium, and the were directly injected into the spleen of Rag2 mice as previously described (Yoshida et al., 2003). One week later, the same number of DCs pulsed with the same antigens were inoculated again into the spleen. One week later, mice were sacrificed, blood was collected by cardiocentesis, and human $\mathrm{CD}^{+}{ }^{+} \mathrm{T}$ cells were enriched from splenocytes using a human $\mathrm{CD}^{+} \mathrm{T}$ cell isolation kit according to the manufacturer's instructions. For the measurement of antigen-specific human cellular immune responses, human CD4 ${ }^{+} \mathrm{T}$ cell $\left(2 \times 10^{5}\right.$ cells) collected from the spleens of immunized Rag2 $2^{-/}$mice were cultured for 2 days with autologous monocytes $\left(2 \times 10^{5}\right.$ cells $)$ in the presence or absence of inactivated HIV containing $40 \mathrm{ng} / \mathrm{ml}$ of p24 in $500 \mu \mathrm{l}$ of RPMI medium supplemented with $20 \mathrm{U} / \mathrm{ml}$ of IL2 in individual wells of a 48 -well plate at $37^{\circ} \mathrm{C}$. The concentration 
of human IFN- $\gamma$ or IL-4 produced in the culture supernatants was determined with ELISA kits.

\section{STATISTICAL ANALYSIS}

Data were analyzed by Student's $t$ test with the with Prism software (GraphPad Software Inc., San Diego, CA, USA).

\section{RESULTS}

\section{GENERATION OF MYELOID MATURE DCs DIRECTLY FROM PBMCs} WITHIN 2 DAYS

In order to reduce the cost, labor and any loss of potential precursors from PBMCs, we have previously established a novel culture method for generating functional human DCs from unfractionated PBMC in which whole PBMCs were cultured in the presence of IL-4 and GM-CSF for 5 days followed by a 2-day maturation in media containing poly I:C and IL-1 $\beta$ (Kodama et al., 2010). However, there were considerable lot variations in commercial poly:IC in the DC-maturation activity (data not shown). Therefore, we tested a previously reported maturation cytokine cocktail containing TNF- $\alpha$, IL-1 $\beta$, IL- 6 and PGE2 (Jonuleit et al., 1997). In a preliminary study, we found that IL6 was not necessary to mature DCs from purified monocytes in the present cell culture conditions, probably due to the use of serum-containing media. Thus, we used a cytokine cocktail

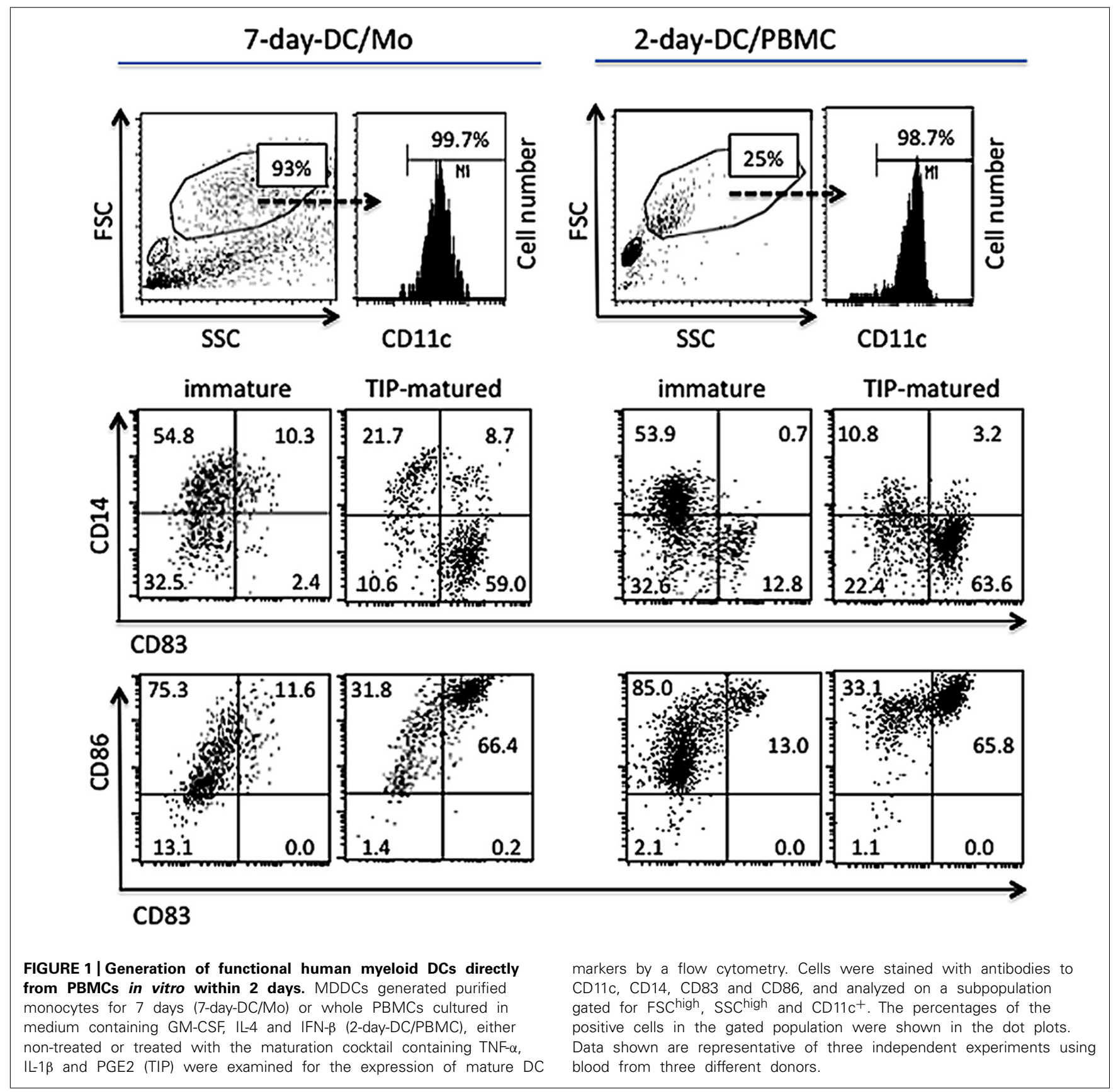


containing $10 \mathrm{ng} / \mathrm{ml}$ of TNF- $\alpha, 10 \mathrm{ng} / \mathrm{ml}$ of IL- $1 \beta$ and $1 \mu \mathrm{g} / \mathrm{ml}$ of PGE2 (hereafter called TIP cocktail) throughout the present study.

Based on our previous report that monocytes can be differentiated into mature DCs within 2 days (Zhang et al., 2008), we tested whether Th1-inducing DCs could be generated from unfractionated PBMCs. PBMCs $\left(2.5 \times 10^{6}\right.$ cells $\left./ \mathrm{ml}\right)$ were cultured in RPMI medium containing GM-CSF (20 ng/ml), IL-4 $(20 \mathrm{ng} / \mathrm{ml})$ and IFN- $\beta(1,000 \mathrm{U} / \mathrm{ml})$ for 1 day followed by additional 1 day cultivation in the presence or absence of the TIP cocktail. The phenotypes of $\mathrm{CD}_{11 c^{+}}$large cells in these 2-day PBMC cultures were compared with those of MDDCs derived from purified monocyte for 7 days (7-day-DC/Mo; Figure 1). The proportion of FSC ${ }^{\text {high }}$ and SSC ${ }^{\text {high }}$ cells in the 2-day-DC/PBMC culture was $20 \sim 25 \%$ of total viable cells depending on donors and these cells expressed CD11c (data not shown). After maturation with the TIP cocktail, similar to the 7-day-DC/Mo, the large $\mathrm{CD} 11 \mathrm{c}^{+}$cells in the 2-day PBMC cultures became CD14 ${ }^{\text {low }}$, CD86 ${ }^{\text {high }}$ and CD83 ${ }^{\text {high }}$, a typical marker of matured myeloid DCs (Ohshima et al., 1997). The other viable cell populations in the 2day PBMC cultures were CD3 ${ }^{+}$T cells $(54.0 \sim 59.2 \%), \mathrm{CD}^{+} 6^{+} \mathrm{NK}$ cells $(8.4 \sim 9.3 \%)$ and $\mathrm{CD} 19^{+} \mathrm{B}$ cells $(6.5 \sim 8.6 \% ; n=3)$. These data showed that the present culture method was applicable to generate myeloid mature DCs from bulk PBMCs within 2 days (2-day-DC/PBMC).

Then we tested cytokine production by these 2-day-DC/PBMC. Interestingly, in contrast to the DCs matured in the presence of LPS, the production of IL-12 and IL-10 by the TIP matured 2-day$\mathrm{DC} / \mathrm{P}$ was minimum (Figure 2). To investigate whether the 2-dayDC/PBMC were immunologically functional, we examined their ability to stimulate allogeneic T cell proliferation. Like the MDDCs (7-day-DC/Mo), the 2-day-DC/PBMC could stimulate allogeneic $\mathrm{T}$ cell proliferation (Figure 3A). Then we quantitated the levels of IFN- $\gamma$ and IL- 4 in the culture supernatants from allogeneic CD $4^{+}$
T cells co-cultured with various DCs. As shown in Figure 3B, among the four DC preparations including the 7-day-DC/Mo, 7-day-DCs from PBMCs (7-day-DC/PBMC), 2-day-DCs from monocytes (2-day-DC/Mo) and 2-day-DC/PBMC, the 2-day$\mathrm{DC} / \mathrm{PBMC}$ were most potent in induction of IFN- $\gamma$ production. The bulk 2-day-DC/PBMC alone did not produce detectable IFN$\gamma(<20 \mathrm{pg} / \mathrm{ml})$ in the present culture conditions (data not shown). The levels of IL- 4 and IL-10 were below detection $(<5 \mathrm{pg} / \mathrm{ml})$ in all the samples tested (data not shown). These results indicated that the 2-day-DC/PBMC had a potential to induce Th1 response.

\section{INDUCTION OF HIV-1-REACTIVE HUMAN CD4 ${ }^{+}$T CELL RESPONSES IN hu-PBL-SCID MICE}

Finally, we examined whether the short-term generated 2-day$\mathrm{DC} / \mathrm{PBMC}$ could induce HIV-1-reactive immune responses in vivo in comparison to MDDCs (7-day-DC/Mo) using our hu-PBLSCID mice model (Yoshida et al., 2003). SCID mice were intrasplenically transplanted with DCs loaded with AT-2-inactivated HIV-1 together with autologous fresh PBMCs. On day 7, these mice were received an intra-splenic booster injection with similarly prepared antigen-pulsed DCs. Seven days after the booster injection, mice were sacrificed and examined for antigen-specific human immune responses. Figure 4 showed that after in vitro re-stimulation with autologous APCs pulsed with inactivated HIV-1, enriched human $\mathrm{CD}^{+}{ }^{+} \mathrm{T}$ cells from two out of three mice immunized with MDDCs (7-day-DC/Mo) pulsed with HIV1 and those from three out of four mice immunized with 2-day-DC/PBMC pulsed with HIV-1 produced IFN- $\gamma$ in antigendependent way, indicating that the 2-day-DC/PBMC could induce $\mathrm{HIV}-1$ antigen-reactive human $\mathrm{T}$ responses in vivo as potent as MDDCs. In the re-stimulated culture supernatants, no IL-4 or IL-10 was detected $(<5 \mathrm{pg} / \mathrm{ml})$ using ELISA (data not shown). In addition, no detectable antibodies against HIV-1 were detected

\section{IL-12 production}

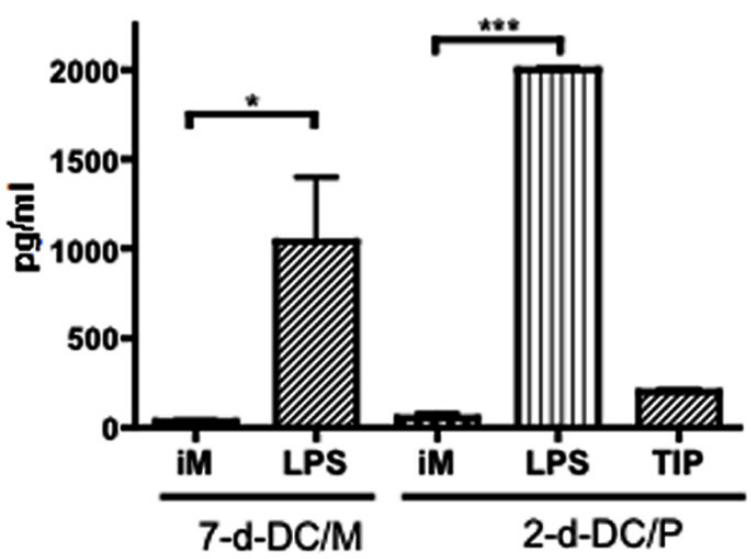

FIGURE 2 | Production of cytokines by the 2-day-DC/PBMC. The levels of IL-12 (bioactive p70 heterodimer) and IL-10 in the supernatants from MDDCs (7-d-DC/M) or 2-day-DC/PBMC (2-d-DC/P) either non-matured (iM) or matured

\section{IL-10 production}

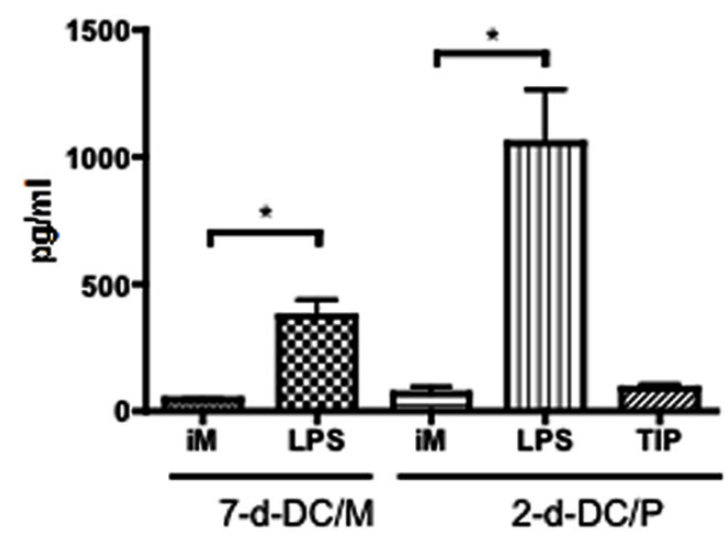

with LPS or the TIP cocktail were determined by ELISA. Data are mean \pm SD of triplicate cultures. ${ }^{*} P<0.05,{ }^{*}{ }^{*} P<0.001$. Data shown are representative of three independent experiments using blood from two different donors. 


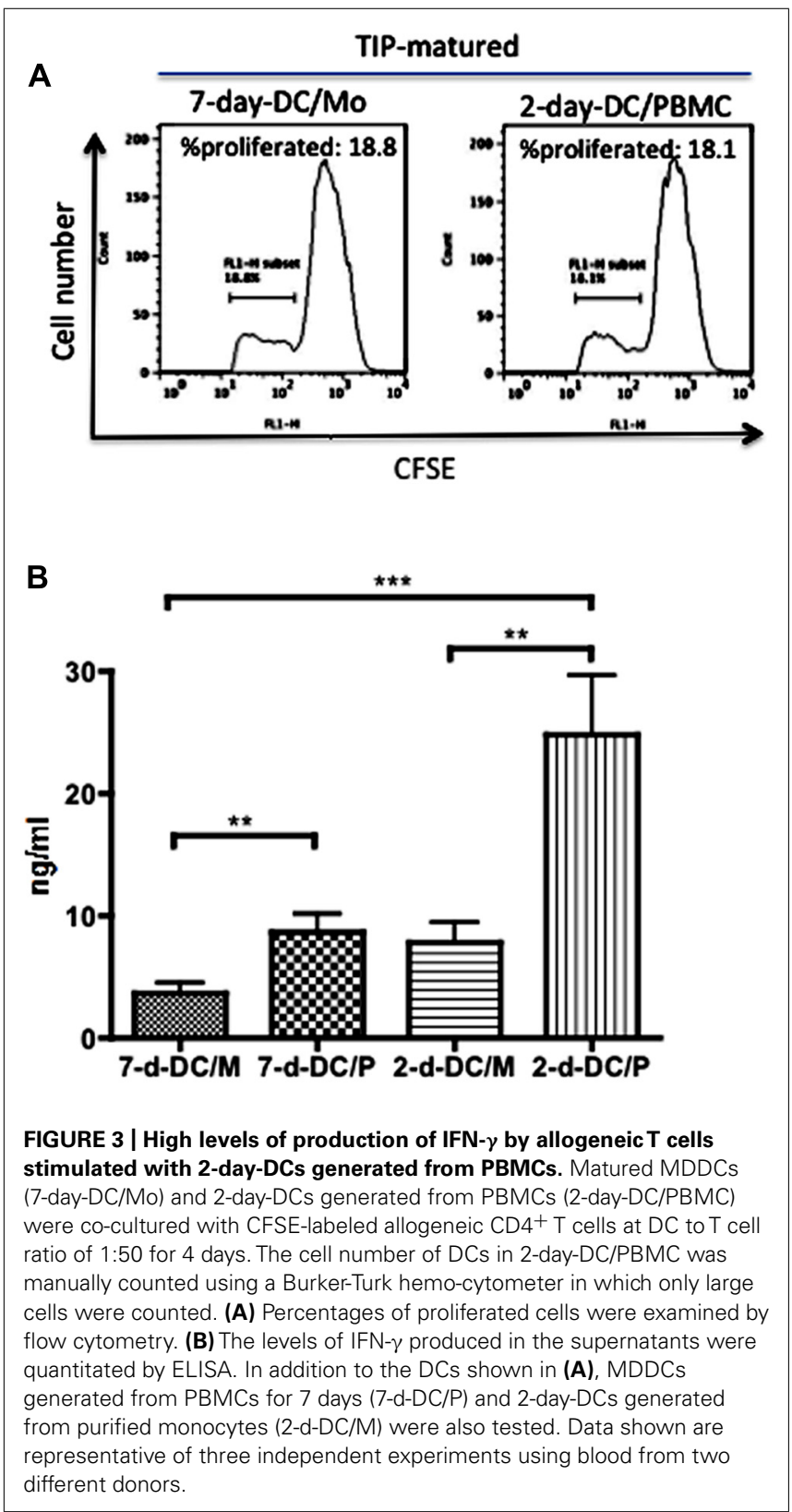

as determined by using a commercial Western blot assay kit in plasma samples from all the DCs-HIV-1-immunized mice (data not shown).

Altogether, these results demonstrated that human myeloid DCs directly generated from PBMCs by the present short-term cultivation method were potent in induction of functional Th1 responses both in vitro and in vivo.

\section{DISCUSSION}

In the present study, we have developed a novel, simple and rapid protocol for generating Th1-stimulating human myeloid DCs directly from unfractionated PBMCs. These 2-day-DC/PBMC were potent in both stimulating allogeneic $\mathrm{T}$ cells in vitro and inducing HIV-1-reactive Th1 responses in hu-PBL-SCID mice.
The use of whole PBMCs as DC precursors might reduce any loss of monocytes in the step of purification by adherence (Jonuleit et al., 2001), elutriation (Berger et al., 2005) or positive or negative selection using immunomagnetic beads (Babatz et al., 2003). One possible concern on using whole PBMCs was that the nonmonocyte cells, such as T, B or NK cells, in the PBMCs might interfere with differentiation and function of DCs. However, in the present study there was no obvious difference in DC maturation and function between in PBMC and purified monocyte cultures.

For the final maturation, we used a cytokine cocktail containing TNF- $\alpha$ and IL-1 $\beta$ and PGE2 (TIP coctail). Simultaneous use of these three reagents in TIP was essential for maturation of DCs since use of the reagents either in single or in two combinations failed to mature DCs (data not shown). In general, IL-6 that is included in the maturation cytokine cocktail TNF- $\alpha$ and IL- $1 \beta$ and PGE2 to mature DCs was not necessary in the present culture conditions. The reason remains to be studied, but it is possible that IL- 6 is required in serum-free culture conditions. The present 2-day-DC/PBMC matured by TIP produced lower IL-12 than those matured by LPS. Low levels production of IL12 might be ascribed to the use of PGE2 that inhibits bioactive IL-12 heterodimer production (Kalinski et al., 2001; Kalim and Groettrup, 2013). Despite of the low level production of IL-12, the TIP-matured 2-day-DC/PBMC were potent in stimulating IFN$\gamma$, but not IL-4 or IL-10, production by allogeneic T cells. The reason for higher potentials of 2-day-DC/PBMC to induce Th1 cells than MDDCs remains to be clarified. It is speculated that natural DCs contained in the 2-day-PBMC-derived DCs might enhance the activation. Indeed, 2-day-DC/PBMC culture generated from $\mathrm{CD}_{14}{ }^{+}$cell-depleted PBMCs were able to stimulate allogeneic $\mathrm{CD}^{+}{ }^{+} \mathrm{T}$ cells to a lesser extent (data not shown). However, we cannot clearly determine if the stimulation was mediated by remaining monocytes. Further study is required to solve this issue. Importantly, as the previous study (Yoshida et al., 2003), the present study showed the induction of primary HIV-1-specific human $\mathrm{CD}^{+} \mathrm{T}$ cell immune responses in hu-PBL-SCID mice by DC-based immunization, demonstrating that the present 2day-PBMC-derived DCs might have a potential for clinical use in DC-based immunization in humans against HIV-1. It was of interest that the levels of IFN- $\gamma$ production were higher in $\mathrm{CD} 4^{+}$ $\mathrm{T}$ cells immunized with 2-day-DC/PBMC than those immunized with 7-day-DC/Mo. It is possible that 2-day-DC/PBMC could live longer than 7-day-DC/Mo in vivo to stimulate antigenspecific $\mathrm{CD}^{+} \mathrm{T}$ cells. In addition, because myeloid DCs are susceptible to HIV-1 infection (Knight et al., 1990), the use of these IFN- $\beta$-treated DCs will be beneficial for HIV-1-infected individuals.

In conclusion, the present study provided a new method to generate functional human myeloid DCs directly from PBMCs in a short-term culture period. These DCs will be useful for studies exploring potentials of DC-based immunization for not only infectious diseases but also cancers in vitro and in vivo.

\section{ACKNOWLEDGMENTS}

This work was supported by the Grant-in-Aid from the Ministry of Education, Culture, Sports, Science, and Technology of Japan. 
7-day-DC/Mo

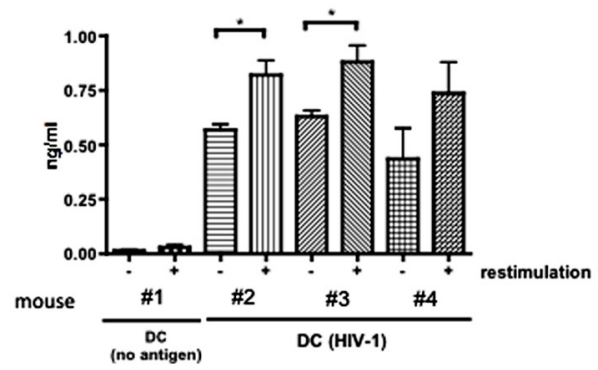

FIGURE 4 | Functional activity of the 2-days-DCs in hu-PBL-SCID mice. Fresh autologous PBMCs from normal human donors were transferred into the Rag2 $2^{-1-}$ mouse spleen together with autologous mature MDDCs (7-day-DC/Mo) or 2-days-PBMC-derived DCs (2-day-D/PBMC) pulsed with no antigen (no antigen) or AT-2-inactivated HIV-1 (40 ng of p24). On day 7 after the first transplantation, these mice were received an intra splenic booster injection with similarly prepared DCs. Seven days after the booster injection,

\section{2-day-DC/PBMC}

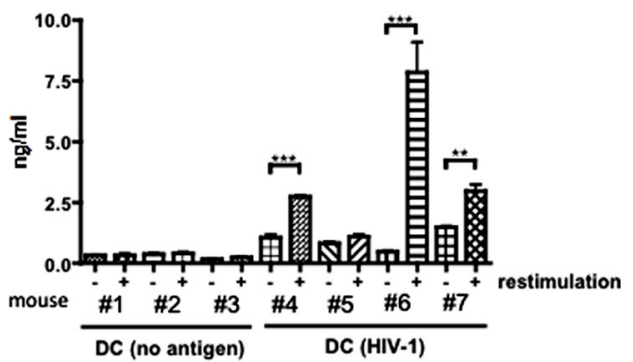

mice were sacrificed and human $\mathrm{CD}^{+}{ }^{+} \mathrm{T}$ cells were purified from splenocytes. These $\mathrm{CD}^{+}{ }^{+} \mathrm{T}$ cells were co-cultured with autologous APCs (adherent PBMCs) in the presence or absence of antigens (restimulation) for 2 days at $37^{\circ} \mathrm{C}$. IFN- $\gamma$ levels produced in the culture supernatants were measured by ELISA. Data show mean \pm SD of triplicate cultures. ${ }^{*} P<0.05$, ${ }^{*} P<0.01,{ }^{* *} P<0.001$. Data shown are representative of three independent experiments using blood from two different donors.

\section{AUTHOR CONTRIBUTIONS}

Akira Kodama designed and performed the experiments, analyzed the data and wrote the paper. Reiko Tanaka and Mineki Saito performed the experiments, analyzed the data and wrote the paper.

\section{REFERENCES}

Babatz, J., Rollig, C., Oelschlagel, U., Zhao, S., Ehninger, G., Schmitz, M., et al. (2003). Large-scale immunomagnetic selection of CD14+ monocytes to generate dendritic cells for cancer immunotherapy: a phase I study. J. Hematother. Stem Cell Res. 12, 515-523. doi: 10.1089/ 152581603322448222

Banchereau, J., Briere, F., Caux, C., Davoust, J., Lebecque, S., Liu, Y. J., etal. (2000). Immunobiology of dendritic cells. Annu. Rev. Immunol. 18, 767-811. doi: 10.1146/ annurev.immunol.18.1.767

Berger, T. G., Strasser, E., Smith, R., Carste, C., Schuler-Thurner, B., Kaempgen, E., etal. (2005). Efficient elutriation of monocytes within a closed system (Elutra) for clinicalscale generation of dendritic cells. $J$. Immunol. Methods 298, 61-72. doi: 10.1016/j.jim.2005.01.005

Connolly, N. C., Whiteside, T. L., Wilson, C., Kondragunta, V., Rinaldo, C. R., and Riddler, S. A. (2008). Therapeutic immunization with human immunodeficiency virus type 1 (HIV-1) peptide-loaded dendritic cells is safe and induces immunogenicity in HIV-1-infected individuals. Clin. Vaccine Immunol. 15, 284-292. doi: 10.1128/CVI.00221-07 Dauer, M., Obermaier, B., Herten, J., Haerle, C., Pohl, K., Rothenfusser, S., et al. (2003a). Mature dendritic cells derived from human monocytes within 48 hours: a novel strategy for dendritic cell differentiation from blood precursors. J. Immunol. 170, 4069-4076.

Dauer, M., Pohl, K., Obermaier, B. Meskendahl, T., Robe, J., Schnurr M., etal. (2003b). Interferonalpha disables dendritic cell precursors: dendritic cells derived from interferon-alpha-treated monocytes are defective in maturation and T-cell stimulation. Immunology 110, 3847. doi: 10.1046/j.1365-2567.2003. 01702.x

Dauer, M., Schnurr, M., and Eigler, A. (2008). Dendritic cell-based cancer vaccination: quo vadis? Expert Rev. Vaccines 7, 1041-1053. doi: 10.1586/14760584.7.7.1041

Ezzelarab, M., and Thomson, A. W (2011). Tolerogenic dendritic cells and their role in transplantation. Semin. Immunol. 23, 252-263. doi: 10.1016/j.smim.2011.06.007

Gilboa, E. (2007). DC-based cancer vaccines. J. Clin. Invest. 117, 1195-1203. doi: 10.1172/JCI31205

Jarnjak-Jankovic, S., Hammerstad, H., Saeboe-Larssen, S., Kvalheim, G. and Gaudernack, G. (2007). A full scale comparative study of methods for generation of functional dendritic cells for use as cancer vaccines. $B M C$ Cancer 7:119. doi: 10.1186/14712407-7-119

Jonuleit, H., Giesecke-Tuettenberg, A., Tuting, T., Thurner-Schuler, B., Stuge, T. B., Paragnik, L., et al.

Aftab A. Ansari participated in the design of the study and helped to draft the manuscript. Yuetsu Tanaka designed and supervised the research, performed experiments and wrote the paper. All authors checked the final version of this manuscript.

(2001). A comparison of two types of dendritic cell as adjuvants for the induction of melanoma-specific $\mathrm{T}$ cell responses in humans following intranodal injection. Int. J. Cancer 93, 243-251. doi: 10.1002/ijc.1323

Jonuleit, H., Kuhn, U., Muller, G., Steinbrink, K., Paragnik, L., Schmitt, E., et al. (1997). Pro-inflammatory cytokines and prostaglandins induce maturation of potent immunostimulatory dendritic cells under fetal calf serum-free conditions. Eur. J. Immunol. 27, 3135-3142. doi: 10.1002/eji.1830271209

Kalantari, T., Kamali-Sarvestani, E., Ciric, B., Karimi, M. H., Kalantari, M., Faridar, A., et al. (2011). Generation of immunogenic and tolerogenic clinical-grade dendritic cells. Immunol. Res. 51, 153-160. doi: 10.1007/s12026-011-8255-5

Kalim, K. W., and Groettrup, M. (2013). Prostaglandin E2 inhibits IL-23 and IL-12 production by human monocytes through downregulation of their common $\mathrm{p} 40$ subunit. Mol. Immunol. 53, 274 282. doi: 10.1016/j.molimm.2012. 08.014

Kalinski, P., Vieira, P. L., Schuitemaker, J. H., De Jong, E. C., and Kapsenberg, M. L. (2001). Prostaglandin E(2) is a selective inducer of interleukin-12 p40 (IL-12p40) production and an inhibitor of bioactive IL-12p70 heterodimer. Blood 97, 3466-3469. doi: 10.1182/blood.V97.11.3466
Knight, S. C., Macatonia, S. E., and Patterson, S. (1990). HIV I infection of dendritic cells. Int. Rev. Immunol. 6, 163-175. doi: 10.3109/08830189009056627

Kodama, A., Tanaka, R., Zhang, L. F., Adachi, T., Saito, M., Ansari, A. A., et al. (2010). Impairment of in vitro generation of monocyte-derived human dendritic cells by inactivated human immunodeficiency virus-1: involvement of type I interferon produced from plasmacytoid dendritc cells. Hum. Immunol. 71, 541-550. doi: 10.1016/j.humimm.2010.02.020

Moll, H., and Berberich, C. (2001). Dendritic cells as vectors for vaccination against infectious diseases. Int. J. Med. Microbiol. 291, 323-329. doi: 10.1078/1438-4221-00138

Ohshima, Y., Tanaka, Y., Tozawa, H., Takahashi, Y., Maliszewski, C., and Delespesse, G. (1997). Expression and function of OX40 ligand on human dendritic cells. J. Immunol. 159, 3838-3848.

Sallusto, F., and Lanzavecchia, A. (1994). Efficient presentation of soluble antigen by cultured human dendritic cells is maintained by granulocyte/macrophage colony-stimulating factor plus interleukin 4 and downregulated by tumor necrosis factor alpha. J. Exp. Med. 179, 1109-1118. doi: 10.1084/jem.179.4.1109

Steinman, R. M., and Banchereau, J. (2007). Taking dendritic cells into 
Kodama et al.

Generation of dendritic cells directly from PBMC

medicine. Nature 449, 419-426. di: 10.1038 /natur e06175

Tanka, R., Takahashi, Y., Kodama, A., Saito, M., Ansari, A. A., and Tanka, Y. (2010). Suppression of CCR5-tropic HIV type 1 infection by OX40 stimulation via enhanced production of beta-chemokines. AIDS Res. Hum. Retroviruses 26, 1147-1154. do: 10.1089/aid.2010. 0043

Tawab, A., Fan, Y., Read, E. J., and Kurlander, R. J. (2009). Effect of ex vive culture duration on phenotype and cytokine production by mature dendritic cells derived from peripharal blood monocytes. Transfusion 49, 536-547. doa: 10.1111/j.15372995.2008.02020.x

Traggiai, E., Chicha, L., Mazzucchelli, L., Bronz, L., Piffaretti, J. C., Lanzavecchia, A., et al. (2004).
Development of a human adptive immune system in cord blood cell-transplanted mice. Science 304, 104-107. doit: 10.1126/science.109 3933

Yoshida, A., Tanka, R., Murakami, T., Takahashi, Y., Koyanagi, Y., Nakamura, M., et al. (2003). Induction of protective immune responses against R5 human immunodeficiency virus type 1 (HIV-1) infection in hu-PBLSCID mice by intrasplenic emunization with HIV-1-pulsed dendritic cells: possible involvement of a novel factor of human CD4(+) Tcell origin. J. Virol. 77, 8719-8728. doa: $\quad 10.1128 /$ JVI.77.16.8719-8728. 2003

Chang, L. F., Okuma, K., Tanaka, R., Kodama, A., Kondo, K., Ansari, A. A., et al. (2008). Genration of mature dendritic cells with unique phenotype and funcion by in vito short-term culture of human monocytes in the presence of interleukin-4 and interferonbeta. Exp. Biol. Med. (Maywood) 233, 721-731. doa: 10.3181/0712-RM-333

Conflict of Interest Statement: The authors declare that the research was conducted in the absence of any commercial or financial relationships that could be construed as a potential conflick of interest.

Received: 25 June 2013; accepted: 10 September 2013; published online: 27 September 2013.

Citation: Kodama A, Tanaka $R$, Sarto M, Ansari AA and Tanaka Y (2013) A novel and simple method for generation of human dendritic cells from unfractionated peripheral blood mononuclear cells within 2 days: its application for induction of $\mathrm{HIV}$-1-reactive $\mathrm{CD}^{+}$ $T$ cells in the hu-PBL SCID mice. Front. Microbial. 4:292. do: 10.3389/ fmicb.2013.00292

This article was submitted to Virology, a section of the journal Frontiers in Microbiology.

Copyright (c) 2013 Kodama, Kanaka, Salto, Ansari and Kanaka. This is an open-access article distributed under the terms of the Creative Commons Attribution License (CC BY). The use, distribution or reproduction in other forums is permitted, provided the origincl authors) or licenser are credited and that the original publication in this journal is cited, in accordance with accepted academic practice. No use, distribution or reproduction is permitted which does not comply with these terms.

www.frontiersin.org

September 2013 | Volume 4 | Article 292 | 7 